\title{
Balancing the Slovak Energy Market After the Adoption of "Fit for 55 Package"
}

\author{
Stanislav Zabojnik ${ }^{1, *}$, Marius Hricovsky ${ }^{2}$ \\ ${ }^{1}$ University of Zilina, The Faculty of Operation and Economics of Transport and Communications, \\ Department of Economics, Univerzitna 8215/1, 01026 Zilina, Slovakia \\ ${ }^{2}$ Attorney in Law and external lecturer, Gorkeho 15, Bratislava, Slovakia
}

\begin{abstract}
Research background: Slovak energy sector is based on older strategic documents setting national interests within energy policy and energy security (before 2014). "Fit for 55 package" proposed by European Commission in July 2021 is one of the most politically ambitious projects after WW2 and brings crucial changes for EU27 energy systems, especially for CEE countries.

Purpose of the article: To analyze the potential impact of the "Fit for 55 package" objectives and consequences on the energy system of the Slovak Republic in terms of fossil fuels substitutes.

Methods: Authors use Energy Balance Sheet (EBS) to outline the unprecedented impact of the EU policy on the Slovak energy system and alternative scenarios for its development. Simulating the impact of $\mathrm{CO} 2$ emissions cuts via Gretl software, the authors outline crucial changes in the energy system and subsequent energy shortages within the Slovak energy market, which have to be replaced (in electricity generation, natural gas, and transportation fuels).

Findings \& Value added: According to the authors' findings, possible substitutes (hydrogen or renewable energy sources) will not fully cover the future demand, and authors suggest possible solutions. Secondly, the impact on transportation capacities and energy transportation corridors are outlined. Finally, the authors stress that political efforts oversize economic and energy reality, especially in Slovakia, and policymakers should better consider the specifics of the CEE energy systems and allocate financial grants for the upgrade of transport corridors
\end{abstract}

Keywords: Slovak energy market; Fit for 55; energy security

JEL Classification: F10; F13; F60

* Corresponding author: stanislav.zabojnik@euba.sk 


\section{Introduction}

Niels Bohr, the Nobel laureate for Physics, is quoted as saying: "Prediction is challenging, especially if it is about the future!". This is valid and also invalid. Especially in recent times, it is pretty simple to find a scheme, which fits precisely with the data from the required results point of view.

Long-term campaign related to prevention of the climatic changes, German "Energiewende" and the energy policy designed by the European Commission has significant consequences for energy and industrial competitiveness (stressed by Fojtikova, 2014 and Fojtikova-Stanickova, 2017), agriculture a real life of the ordinary people. Measures applied on various sectors of the industry have particular impacts on the specific areas, but they are also resulting in general changes of the industry, agriculture, transport, logistics, and all other parts of the economic life in Europe. We are working with pre premise that energy means life in its primary substance. Energy is also assisting humankind in all areas of development and is logically directly connected to the productivity of the labor, economic growth, and wellbeing of the people.

In this text, we will use the definition of energy security as a situation, when we have energy in every form to disposal in the time, when we need it, in the quantity we do need, under competitive price conditions (related to the global markets) in the optimal energy mix, with reserves, which enables to endure possible crises and with alternative suppliers.

Without a doubt, the epochal changes within the core topic of the EU integration - energy security, will determine the quality of the standard of living based on safe, reliable, and price competitive energies. Especially for the European industrial producers, this seems to be a crucial question. On the other hand, price development in the second half of 2021 revealed a fragile future of the decarbonized EU quickly. This is particularly valid for the CEE countries due to the lower standard of the living, firm position of the industry within GDP creation, and insufficient innovation activity of domestic industrial companies. Besides this, the Fit for $55^{1}$ package seems to accelerate the challenges not only for the industrial player but also for the energy system itself. Since the goals were set at the EU level, individual countries impacted by the changes have to be observed to outline potential threats and challenges for the smaller economies like the Slovak Republic.

\section{Literature review and Methodology}

Since the Kyoto protocol adoption, more authors stressed the potentially negative impact on the energy systems and general economic growth. Some of them (O'Neill, 2018 and Mastini et al., 2021) stress that the debates are mostly "degrowth narratives" considering climate stabilization as a way for lower GDP (using conventional GDP methods) and proved that economic growth could be feasible even applying more rigid environmental standards. On

\footnotetext{
1 The Fit for 55 package, published on July 14, 2021, includes the following legislative proposals and policy initiatives: 1. a revision of the EU emissions trading system (EU ETS), including its extension to shipping, revision of the rules for aviation emissions and establishing a separate emission trading system for road transport and buildings, 2. a revision of the effort sharing regulation on member states' reduction targets in sectors outside the EU ETS, 3. a revision of the regulation on the inclusion of greenhouse gas emissions and removals from land use, land use change and forestry (LULUCF), 4. a revision of the renewable energy directive, 5. a recast of the energy efficiency directive, 6. a revision of the directive on the deployment of alternative fuels infrastructure, 7. an amendment of the regulation setting $\mathrm{CO}_{2}$ emission standards for cars and vans, 8. a revision of the energy tax directive, 9. a carbon border adjustment mechanism, 10. ReFuelEU Aviation for sustainable aviation fuels, 11. FuelEU Maritime for a green European maritime space, 12. a social climate fund (EC, 2021).
} 
the other, especially the authors from EU after 2005 (Baláž, 2007 and Zábojník-Borovská 2020) stress the potential impact of ambitious and quick changes in the EU energy policy not only on energy systems but general export competitiveness of V4 industrial countries. Confronting this statement, Skjaerseth (2021) suggests that related policies have progressed despite member state opposition, developing from different climate and energy policies to coordinated policy mixes or packages. Among all EU member countries, the V4 economies record an average rating in the implementation of the energy and climate framework. Slovakia and Hungary are ranked the highest, Poland and the Czech Republic - the lowest (2019).

There is a strong relationship between energy security and competitiveness or export competitiveness of the V4 countries. Nyga-Lukaszewska and Przeździecka (2017) confirmed the existence of the statistically significant relationship between energy security and export, at least at the level of some industries or commodity groups. Therefore, energy policy has to reflect the interest of the EU exporters, especially within the countries having lower GDP p. c. Notwithstanding, more authors have been proving the positive impact of decarbonization ambitious goals of the EU in different areas as direct and indirect benefits. The benefits comprise the level of society as a whole (such as health effects, new jobs, impact on climate change, improving energy security) (Berto et al., 2020; Dell'Anna, 2020). E. g., the most recent study published by International Renewable Energy Agency indicated that renewable energy provided 11.5 million jobs worldwide in 2019, 0.5 million more than in 2018 (IRENA, 2020).

European Commission launched more revolutionary changes in the EU energy system after 2014 (energy union concept, Winter package, and finally Fit for 55 packages in 2021). The set of policies, especially the most recent one, aim to become EU climate neutral in 2050. This has brought crucial questions like if it is feasible within the EU (energy systems and competitiveness) and, especially at the V4 level, what might be possible implications in terms of asymmetric shocks (different impact of stringent environmental policy in more prosperous and less developed countries of the EU). Trying to explain and deal with these challenges, several works at the global level impact (Aghahosseini et al., 2019, Esteban et al., 2018) or even directly researching the effect of neutral climate scenarios - mostly 100 RES share directly applying the economies of the EU (Wood et al., 2020; Moran et al., 2020; Weber et al., 2017 and more). These studies revealed several challenges for the EU energy systems, mostly concluding the necessary storage systems to balance energy systems.

For the last years, studies indicating rather more complicated movement towards the climate-neutral economies have been identified within V4 countries. Streimikiene (2021) analyzed the main problems for these countries in implementing targets set by the energy and climate package. The author stress that the Czech Republic was the leading country in penetration of renewables and Slovakia was the most advanced country in terms of energy efficiency improvements while in term of GHG emission reduction countries have achieved similar results and obtained the same sum of ranks (Streimikiene (2021). Besides this study suggesting higher usage of nuclear power to meet the goals of Fit for 55 packages.

Nevertheless, the most recent studies revealed that the COVID-19 pandemic rather helped the RES implementation in terms of energy systems stability since during the COVID-19 pandemic, a relatively higher grid capacity resulting from a decreased electricity consumption, in particular, may have contributed to grid stability (Halbrugge et al., 2021).

Based on the literature findings and literature gap related to V4 economies under Fit for 55 implementations or directly to the economy of the Slovak Republic, the authors decided to analyze the challenges of the extremely challenging goals of the most recent package. The paper aims to comprehensively discuss the EU Fit for 55 package's impact till 2030, taking into account the general goals applied and investigated at the Slovak economy and national energy balance level. The motivation for the research lies in the powerful implication for 
policy design. Based on the recommendations of Streimikiene et al. (2021), the authors used the database of the National Energy Balances Sheets of the EU (2021) and Integrated National Energy and Climate Plan for $2021-2030$. The authors assumed a $-20 \%$ decrease of gasoline and diesel till 2030 and the same rate for 2035, expect higher consumption of natural gas, $10 \%$ lower consumption of LPG for transportation purposes, and higher usage of advanced biofuels and hydrogen (priority of the Slovak government). All the energy cuts from the mentioned categories are expected to be compensated by electricity usage (battery electric vehicles) and decarbonization of the industrial production, replacing fossil fuels usage with "green" electricity consumption (primarily from RES). All the calculations were realized within MS Excel and Gretl to forecast potential changes of those two databases after their update due to Fit for 55 proposals.

\section{Results}

On 14 July, the European Commission published a new climate and energy legislative package change that have problems making the EU a carbon-neutral continent by 2050. It follows on from the EGD of December 2019 and the commitment to make the EU a carbonneutral continent by 2050. The package sets targets for 2030 and announced earlier greenhouse gas emissions by 55\% compared to 1990 (currently 40\%).

The package contains 13 legislative proposals, which modify existing legislation but bring a whole new legal framework. Out of 13 proposals, the authors consider the following legislative changes to be the biggest challenge for the Slovak energy system and competitive prices of energy:

1) Revision of the Emissions Trading Scheme (EU ETS). The EU ETS is the main instrument of EU climate policy, determining the price of emissions allowances. Finally, a limit of these was set at 55\% till 2030. An innovative element is the extension of the maritime and road transport, the proposal also included buildings and road transport for the first time. The proposal provoked strong criticism from $\mathrm{CEE}$, which points to an increase in energy poverty (Poland).

2) Amendment to the Renewable Energy Sources Directive (RED) defines two main criteria - what is considered RES and the minimum share, binding target for RES at the level of Member States. The revision has pushed the threshold from the original $32 \%$ to $40 \%$ by 2030 . There are several concerns about reclassifying natural gas to RES ("low carbon fuel").

3) Revision of the Directive on the Deployment of Alternative Fuels Infrastructure (AFID) - proposed forbidden production of ICE cars in EU from 2035. This represents the conditions for creating vehicle infrastructure with an alternative drive, recharging, and refueling across the EU, thereby responding mainly to the trend of electromobility. The document envisages the creation of 1 mil. charging points in the EU by 2025 and 3 mil. charging points by 2030 .

Confronting the initial Integrated National Energy and Climate Plan for 2021 - 2030, the new goals can be forecasted as follows: 
Table 1. Energy balance of the Slovak Republic (current and forecasted)

\begin{tabular}{|c|c|c|c|c|c|c|c|}
\hline \multirow[b]{2}{*}{ Fuel } & \multirow[b]{2}{*}{ Unit } & \multirow[b]{2}{*}{$2017 *$} & \multicolumn{3}{|c|}{$\begin{array}{c}\text { Integrated National Energy and } \\
\text { Climate Plan } \\
\end{array}$} & \multicolumn{2}{|c|}{ Fit for 55 goals } \\
\hline & & & 2020 & 2025 & 2030 & 2030 & 2035 \\
\hline Gasoline & GWh & 6121 & 6041 & 5885 & 5873 & 4698 & 3524 \\
\hline Diesel & GWh & 20749 & 15643 & 15839 & 15790 & 12632 & 9474 \\
\hline LPG & GWh & 540 & 974 & 890 & 933 & 840 & 746 \\
\hline Natural gas & GWh & 62 & 209 & 218 & 300 & 360 & 420 \\
\hline Biogas & GWh & 0 & 1 & 7 & 31 & 31 & 31 \\
\hline Conventional biofuels & GWh & 1801 & 2066 & 2035 & 2205 & 2205 & 2205 \\
\hline Advanced biofuels & GWh & 0 & 0 & 0 & 3 & 6 & 9 \\
\hline Kerosene & GWh & 13 & 630 & 769 & 943 & 943 & 943 \\
\hline Hydrogen & GWh & 0 & 0 & 0 & 3 & 9 & 15 \\
\hline Electricity & GWh & 0 & 196 & 242 & 293 & 4626 & 8959 \\
\hline & & & & & 26375 & 26351 & 26326 \\
\hline
\end{tabular}

Source: authors' calculations based on Integrated National Energy and Climate Plan for $2021-2030$ of the Slovak Republic and proposals within Fit for 55 package

The potential changes of the energy balance of the Slovak Republic are primarily focused on

- Natural gas consumption (as a vital source of $\mathrm{CO} 2$ cuts and enabling to balance the electricity system under control and stable)

- e-mobility (as a replacement of oil-consuming ICE cars)

- electricity production from the RES and less polluting sources than fossil fuels

\section{Discussion}

Slovakia has recently been in a relatively comfortable situation concerning power generation security and also CO2 output. The country is generating around $30 \mathrm{TWh}$ of electricity with a comfortably CO2-clean mix consisting of nuclear energy, water power generation, coal and gas-powered power generation, biomass-powered units, and photovoltaic.

The basic of Slovakia's power output is based upon nuclear-powered generation units $(14,8 \mathrm{TWh})$ in Jaslovske Bohunice 3 and 4 (932 MWe) and Mochovce 1 and 2 (905 MWe). Water power consists of Vah River cascade (7\%) and Gabcikovo - Danube water power plant (800 MWe installed $-10 \%$ ) total $3.9 \mathrm{TWh}$. This generation is extended by coal-powered power plants $(13 \%$ or $3.6 \mathrm{TWh})$ in Novaky (266 Mwe) and partially in Vojany (consists recently of 2 units (1. And 2), with $110 \mathrm{MW}$ generation capacity each plus provision of ancillary services for power system (units 5 . and 6 . with ability to vary the power output from 50 MWe to $110 \mathrm{Mwe}$ - these two units are co-powered by biomass).

Part of the electricity generation is natural gas powered in Malzenice (430 MWe), PPC Bratislava (216 MWe), Levice, Povazska Bystrica, Panicke Dravce. Since 2010 relatively quick extensions of the photovoltaic power plants have been pushed forward through generous subsidies. The total installed capacity is around $530 \mathrm{MWe}$.

Electricity is a part of the energy mix in Slovakia. Another significant element of the energy mix is the oil-based fuels (gasoline, diesel) which are in Slovakia used mainly for the mobility of the population and logistics. The country is using recently around 5 mil. tons of crude oil, which give about 60 TWh total. 99,9\% of all personal cars and trucks in Slovakia 
are gasoline and diesel-fueled. Under precondition, the politics wish to have logistics and mobility compared with the recent one, alternative up to $60 \mathrm{TWh}$ (double of the recently installed power generation capacity) have to be provided, our calculation suggests additional electricity consumption caused primarily by increasing BEV fleet in Slovakia of about $9 \mathrm{TWh}$ until 2035. Even if we calculate with the electromobility as a more efficient transport mean (the equivalent of the carbohydrate fuel on the level of 2,9 1/100 km in an electric car comparable to $81 / 100 \mathrm{~km}$ by a similar car with a standard engine). Until recently, there has been no relevant policy within the country to replace individual mobility by public means (electricity-powered trains, trams, and busses easily accessible to the public). Taking into account the terms for approvals, problems with land ownership and public procurement, we cannot expect any significant change until 2035, and we may have some doubts concerning 2055. So, in this case, the Commission expects to guarantee the mobility of the workforce, maintain the existing industry, and the competitiveness of the European industry (as proved by Balaz and Bayer, 2019); there is no realistic alternative for feeding 3417572 registered cars in Slovakia today (data for September 2021).

We cannot also forget the production of heat and water. Thanks to the very dense gas network in the country (Balaz, 2007), natural gas is the main fuel used. Slovakia annually uses around $50 \mathrm{TWh}$ of natural gas with an increasing tendency (since the main heat power plants are changing technology from coal to gas and biomass). We expect that for the time being (until 2050), gas will be accepted as an energy source acceptable for the environmentalist. We cannot exclude the tendency of the population to use in higher extend electricity also for heating and warm water preparation, which will create additional pressure on the electricity generation.

What are the possibilities for extensive import of electricity power to Slovakia?

\section{Fit for 55 - EU's Climate turns its climate changes into action plan}

The aim to reduce the greenhouse gas emissions 55\% from 1990 levels by 2030 has been a political wish (e. g. if Poland reduces its emissions by 55\%, it will produce 3-4 times more greenhouse gas than Slovakia) until the green deal and its executive part "Fit for 55" has been prepared.

\section{New energy sources and altrenatives}

What are the possibilities of extending the basis for electricity power generation in Slovakia and increasing the clean electricity supply? Before answering this question, it is necessary to calculate the impact of decommissioning the coal-powered energy units (both electricity and heat production), especially in Novaky and Vojany 1 and 2, which will take around $483 \mathrm{MWe}$ from the net. The heat power plants are recently in the process of transformation from coal-powered to gas and biomass-powered units, even though their contribution to the total electricity output is negligible.

We may expect that in some - more or less distant time - the new nuclear units in Mochovce (3. And 4.) will be put into operation with an additional capacity of $942 \mathrm{MWe}$.

More distant is the possible new nuclear unit in Jaslovské Bohunice to use an existing nuclear power-producing area in Jaslovske Bohunice with a disputed installed capacity up to $1200 \mathrm{MWe}$. This unit and also long-planned 2 generation units in Kecerovce (1200 MWe?). Due to the complexity of the construction of nuclear-powered generation units and the political climate in the European Union (especially by the good neighbor of Slovakia - in Austria), we can express doubts about any possibility of having these units operational until 2055. 
We cannot exclude the fact that under the pressure of decommissioning the coal-powered power plants in the Czech Republic in Poland and in Germany, the political atmosphere may change. However, even under such possible changes, there is no real chance of having any new other than Mochovce 3 and 4 nuclear-powered generation units in Slovakia until 2055. Whether the concept of small, modular nuclear reactors will create new opportunities for implementing nuclear energy is for this article also out consideration. That is why we cannot use it for our calculation other than the existing capacity plus above mentioned Mochovce project.

The extremely hostile position of the recent Slovakian Ministry of Environment related to hydro generation units (even the small ones with the capacity under $5 \mathrm{MWe}$ ) excludes any discussion about new hydro generation units from the realistic discussion for at least two years. Even in the case of the political change, the possibilities for large hydro generation units on the Slovakian territory are more hypothetical and related to the limited hydro potential of the Slovakian rivers (better suitable for smaller units) and the low feasibility of the buildup of any big dam comparable to Gabcikovo or Liptovska Mara. Even smaller units like Žilina hydropower plant (72 MWe) are recently out of the question.

Where is any realistic chance to increase the power generation until 2030 or 2050 ? Natural gas is still accepted as a source of energy due to the European Commission. Construction of the gas generation units (even bigger ones). We have to consider that the environmental (EIA - Environmental Impact Assessment) and construction approval procedure plus the possible shortage of the gas turbines on the suppliers' side may lead to relatively long-term projects. If we seriously consider "Fit for 55" as a long-term program and its realistic targets, there is a chance to start with a significant construction process, which can increase the needed electricity supply until 2030 (prohibition of the gasoline/dieselfueled engines) or 2050.

Another source for clean electricity generation is the whole area of renewable power generation (photovoltaic, wind, solar - as mentioned above, with the current policy, water is excluded). We do calculate for installation of $1 \mathrm{MW}$ approximately in $10.000 \mathrm{sqm}$, and the effectual output is calculated by 1000 max $1200 \mathrm{MWh}$. So, trying to produce the missing 20$30 \mathrm{TWh}$ of power in photovoltaic power generation units, it is necessary to build 30.000 MWe installed capacity, which means $300 \mathrm{mil}$. m2, which equals $300 \mathrm{~km} 2$. Under precondition, the approval procedures are efficient, the problem with the delivery of a sufficient number of photovoltaic units may be the most significant barrier. Using the sun to produce heat and warm water could be mainly related to housing and roof installation. Solar generation units may be connected with heat power plants and serve as subsidiary supporting generation.

Wind power plants in Slovakia are still a new generation field, and we cannot exclude the possibility of extending the power generation by wind units. Due to the fact, there is no practice related to wind conditions on the country's territory, and it is pretty challenging to estimate the relevancy of wind as a source for the process of implementation of the Fit for 55 strategies.

The strategists and experts may say: „If you cannot produce it, import it.” Our traditional trading partner, the Czech Republic, has a significant generation capacity based on coal. Under the pressure of the Commission, it will start to shut down the most CO2-intensive units. The result could be a substantial decrease in production and deficit under current conditions. The Czech Republic will face the same problem as Slovakia, and therefore, to rely on imports from the Czech Republic is not through road.

Poland has an even bigger problem because up to $85 \%$ of electricity is generated in coalpowered power plants. If the Slovakian power generation emission quote is between 120 and $230 \mathrm{gCO} 2 \mathrm{eq} / \mathrm{kWh}$, Czech is between 300 and $450 \mathrm{gCO} 2 \mathrm{eq} / \mathrm{kWh}$, and Polish is higher than $680 \mathrm{gCO} 2 \mathrm{eq} / \mathrm{kWh}$. If Poland tries to reduce the emissions by decommissioning the coal 
power plants, there will be a shortage of electricity supply. If the ongoing tensions between Commission and Poland concerning the justice system in Poland, where the Commission is trying to execute control over the polish justice system, may lead to compromise, Fit for 55 with its consequences may lead to Polish exit as a lifesaving necessity.

Imports from nearly bankrupt Ukraine (Power plant Burschtino) may be realistic but not very secure. With no existing connectivity to Austria (ideologic reasons makes such project almost impossible because of discrepancies concerning nuclear energy) will be even not built) and deficit Hungary reality of importing electricity to cope with the consequences of the "Fit for 55" strategy.

\section{Conclusions}

From 2014, European Commission prioritized environmental issues as a strategic doctrine of its agenda and goals for member countries for the next decades. The project of energy union and Winter package accelerated the stringent environmental objectives. Fit for 55 package presented on July 14th, 2021, revealed the historically ambitious implementation of those goals via legislation. Like a similar project of the EU, this will bring several opportunities, challenges, and threats for the member countries not only in the energy systems but also in the field of general competitiveness.

In recent weeks, turmoil in the global energy markets is just a tiny example of the result of the energy strategy for the EU. The case "Slovakia" is very similar to another European countries, and there is no realistic expectation of increasing the energy generation from other sources but renewable. The priorities of the packages consist of substantial emission cuts, boosting renewable energy sources used, and massive and unprecedented electrification of the EU passenger cars fleet. Especially for the countries like Slovakia (a relatively ideal energy mix with lower than EU average carbon footprint), this could mean massive investment into the energy storage, auxiliary services, and stability of the supplies. There will probably be no severe cuts of the fossil fuel shipments from the Russian Federation, though the intensive rise of BEV can replace the massive consumption of oil products by domestic electricity (primarily from nuclear power plants).

The first conclusion is that there is no realistic expectation of a sufficient increase in electricity generation to replace crude oil and gas, even partially. Planning, projects, EIA, and other construction approvals plus construction excludes stable and reliable increase of the electricity generation on the level at least $8 \mathrm{TWh}$ till 2030 and later as much as $20 \mathrm{TWh}$. If the increase would be based on photovoltaic (unstable and unreliable sources), it would be necessary to build sources for regulatory electricity generation (both positive and negative). Pumping water power plants are again due to the "environment protection" in Slovakia almost with $100 \%$ probability out of the question. Gas generation is the remaining source. All the baseload power plants (with the exemption of the coal-powered, which are to be decommissioned in 2023) have recently substantially lower CO2 emissions than gas-powered units.

Generally, the country will be able to generate or import electricity necessary for electricity-based mobility in 2050. If the production of the ICE vehicles is terminated in 2030, in 2050 , the crude oil or CNG/LNG-based mobility will be long over with no relevant electricity generation and distribution sources. The generation of the electricity is still questionable. Therefore, the conclusion that the Fit for 55 projects will significantly impact logistics and the reliability of the supply of the goods and services for the population is another serious point.

The conclusion, the mobility of the labor force will be limited (the question is to which extend - but much lower than is the case today) is therefore very realistic. To cope with the Fit for 55 requirements (every $60 \mathrm{~km}$ electro charger) and the necessity to transport another 
$20 \mathrm{TWh}$ for mobility will require massive investments in transmission and distribution networks. National transmission system realizing the $200 \mathrm{kV}$ network by $400 \mathrm{kV}$ network recently creating transmission reserve, which will not comply with the 2030 or 2050 requirements. Distribution networks, which were overloaded by the previous increase of the photovoltaic installations, are definitely not ready to collect another $20 \mathrm{TWh}$ new unstable sources and transport them to the electric car charging points that usually require high amperage. Necessary investment is determined by the qualified labor force, able to increase transformation, transmission, and distribution capacity of the national network in Slovakia (almost doubling the current capacity). Besides energy system itself, other potential limitations within the V4 region, particularly in Slovakia, are connected to a harmful effect on the export competitiveness and agriculture production (the commodities dependent on energy inputs).

The costs related to the project are so high, and the return on investment is so long (unless sharply increasing the price of electricity), that the result will be very different from "lowcarbon economic prosperity" and "sustainable growth".

Possible limitations of the research are connected to data access and final commitments stemming from the legislation. A comprehensive map of requirements and impact has to be compiled. Further research can be carried out in the field of electricity production itself, changes within the energy security and securing the energy supplies from the third countries after the package implementation as well as new commodities within the potential import structure (lithium, magnesium, and other commodities essential in BEV production) since Slovakia will be probably a strong automotive assembly player also in the following decades.

\section{Aknowledgement}

This paper is a part of a research project of the Ministry of Education, Family and Sports of the Slovak Republic VEGA (in the period 2020 - 2022) No. 1/0777/20: Belt and Road initiative - opportunity or threat for the EU and Slovak export competitiveness?

\section{References}

1. Aghahosseini, A., Bogdanov, D., Barbosa, L. S., \& Breyer, C. (2019). Analysing the feasibility of powering the Americas with renewable energy and inter-regional grid interconnections by 2030. Renewable and Sustainable Energy Reviews, 105, 187-205.

2. Balaz, P., \& Bayer, J. (2019). Energy Prices and their Impact on the Competitiveness of the EU Steel Industry. Prague economic papers, 2019(5), 547-566.

3. Balaz, Peter. (2007). Energy and Its Impact on the Economic Growth in the World Economy. 1st edition. Bratislava: Sprint-vfra, 2007. 275 pp. ISBN 9788089085873.

4. Berto, R., Stival, C. A., \& Rosato, P. (2020). The valuation of public and private benefits of green roof retrofit in different climate conditions. In Values and Functions for Future Cities (pp. 145-166). Springer, Cham.

5. Dell'Anna, F. (2021). Green jobs and energy efficiency as strategies for economic growth and the reduction of environmental impacts. Energy Policy, 149, 112031.

6. Esteban, M., Portugal-Pereira, J., Mclellan, B. C., Bricker, J., Farzaneh, H., Djalilova, N., ... \& Roeber, V. (2018). 100\% renewable energy system in Japan: Smoothening and ancillary services. Applied energy, 224, 698-707.

7. Eurostat. (2021). National Energy Balance Sheet of the EU. Available on: https://ec.europa.eu/eurostat/web/energy/data/energy-balances 
8. Fojtikova, L. - Stanickova, M. (2017). The EU member states export competitiveness and productivity. Politická ekonomie: teorie, modelování, aplikace, 65(6), 669-689.

9. Fojtikova, L. (2014). Performance and Growth of the Eurozone Export. Procedia Economics And Finance, 12, 154-163.

10. Halbrügge, S., Schott, P., Weibelzahl, M., Buhl, H. U., Fridgen, G., \& Schöpf, M. (2021). How did the German and other European electricity systems react to the COVID19 pandemic?. Applied Energy, 285, 116370.

11. IRENA. (2020). Renewable Energy and Jobs - Annual Review 2020. https://www.irena. org/-/media/Files/IRENA/Agency/Publication/2020/Sep/IRENA_RE_Jobs 2020. Pdf

12. Mastini, R., Kallis, G., \& Hickel, J. (2021). A green new deal without growth?. Ecological Economics, 179, 106832.

13. Moran, D., Wood, R., Hertwich, E., Mattson, K., Rodriguez, J. F., Schanes, K., \& Barrett, J. (2020). Quantifying the potential for consumer-oriented policy to reduce European and foreign carbon emissions. Climate Policy, 20(sup1), S28-S38..

14. Nyga-Łukaszewska, H., \& Chilimoniuk-Przeździecka, E. (2017). Modelling energy security and international competitiveness: The export perspective. Entrepreneurial Business and Economics Review, 5(2), 71.

15. O'Neill, D., et al. (2018). The EU needs a stability and wellbeing pact, not more growth. The Guardian. https://www.theguardian.com/politics/2018/sep/16/the-eu-needsa-stab ility-and-wellbeing-pact-not-more-growth (accessed on October 18th, 2019).

16. Pach-Gurgul, A., \& Ulbrych, M. (2019). Progress of the V4 Countries towards the EU's Energy and Climate Targets in the Context of Energy Security Improvement. Entrepreneurial Business and Economics Review, 7(2), 175-197.

17. Skjærseth, J. B. (2021). Towards a European Green Deal: The evolution of EU climate and energy policy mixes. International Environmental Agreements: Politics, Law and Economics, 21(1), 25-41.

18. Streimikiene, D. (2021). Challenges of Approaching Climate Neutral Society in V4 Countries, Montenegrin Journal of Economics, 17(3), 181-191.

19. Weber, G., \& Cabras, I. (2017). The transition of Germany's energy production, green economy, low-carbon economy, socio-environmental conflicts, and equitable society. Journal of Cleaner Production, 167, 1222-1231.

20. Wood, R., Neuhoff, K., Moran, D., Simas, M., Grubb, M., \& Stadler, K. (2020). The structure, drivers and policy implications of the European carbon footprint. Climate Policy, 20(sup1), S39-S57..

21. Zabojnik, S., \& Borovska, Z. (2020). Competitiveness of the Slovak Republic as a Determinant of its Success in Third Country Markets. In SHS Web of Conferences (Vol. 92). EDP Sciences. 